\title{
INOVASI MODEL-MODEL PEMBELAJARAN BIDANG SAINS UNTUK MENINGKATKAN HASIL BELAJAR MAHASISWA
}

\author{
Oleh: Muh. Khalifah Mustami*
}

\begin{abstract}
The teachers of science should develop teaching process by making innovation on different models of teaching. It is designed to get students interest and develops innovative thinking for a maximum end. With respect to teaching science, teachers should employ analogical approach, use multimedia, and technology based teaching. In addition, the qualification of academics, students, teaching facilities, teaching process, curriculum and controlling are of great importance for effective learning process.
\end{abstract}

KEYWORDS: model pembelajaran, sains, hasil belajar

INOVASI model-model pembelajaran banyak diperbincangkan dalam dunia pembelajaran karena sangat diperlukan, terutama dalam menghasilkan model pembelajaran baru yang dapat memberikan hasil belajar lebih baik, peningkatan efisiensi dan efektivitas pembelajaran menuju pembaharuan. Sering terjadi seorang dosen di perguruan tinggi kurang mempunyai bekal model pembelajaran karena hanya mementingkan penguasaan dan pendalaman materi kuliah serta pengalaman dalam bidang ilmunya, sehingga penyampaian materi kuliah tidak optimum.

Pengalaman pembelajaran yang sering dihadapi di perguruan tinggi adalah bahwa banyak mahasiswa menganggap mata kuliah bidang sains sulit dipelajari, sehingga mahasiswa sudah terlebih dahulu merasa kurang mampu untuk mempelajarinya. ${ }^{1} \mathrm{Hal}$ ini mungkin disebabkan oleh penyajian dosen terhadap materi kuliah yang kurang menarik, membosankan, sulit dan menakutkan sehingga mahasiswa kurang menguasai konsep dasar perkuliahan yang diikutinya, dan akhirnya perkuliahan tersebut menjadi tidak menarik lagi bagi kebanyakan mahasiswa.

Beberapa faktor penyebab kurangnya penguasaan materi perkuliahan bagi mahasiswa diantaranya adalah (1) sistematika dan urutan materi kuliah yang belum mampu memotivasi mahasiswa belajar karena

*Doktor lulusan Jurusan Pendidikan Biologi pada Program Pascasarjana Universitas Negeri Malang ini adalah dosen Fakultas Tarbiyah dan Keguruan dan Program Pascasarjana UIN Alauddin Makassar. 
langsung mengajarkan materi kuliah yang tergolong sulit tanpa memberikan pengertian dasar yang diperlukan (mata kuliah prasyarat), (2) mahasiswa sering belajar dengan cara menghafal tanpa membentuk pengertian terhadap materi kuliah yang dipelajari, (3) materi kuliah yang diajarkan mengambang sehingga mahasiswa tidak dapat menemukan 'kunci' untuk mengerti materi perkuliahan yang sedang dipelajari, dan (4) dosen tertentu kurang berhasil menyampaikan 'konsep' bagi mahasiswa untuk menguasai materi yang diajarkan karena kurangnya penguasaan model pembelajaran. ${ }^{2}$

Sebagai dosen dan orang yang menekuni bidang pembelajaran, maka ia harus selalu waspada terhadap materi kuliah yang sedang dan akan diajarkan kepada mahasiswa. Dengan demikian, selain menyampaikan materi kuliah, seorang dosen harus terbebani untuk mengembangkan topik kuliah agar memberikan hasil belajar yang optimum. ${ }^{3}$ Untuk mengembangkan penguasaan konsep pelajaran yang baik dibutuhkan komitmen mahasiswa dalam memilih belajar menjadi sesuatu yang "berarti", yaitu dengan cara meningkatkan kemauan mahasiswa mencari hubungan konseptual antara pengetahuan yang dimiliki dengan yang dipelajari di dalam perkuliahan. Untuk mencapai tujuan ini maka diperlukan inovasi model pembelajaran yang dapat dipergunakan untuk meningkatkan kemampuan mahasiswa belajar dengan mudah dan efisien berdasarkan pengetahuan dan kemampuan yang dibutuhkan dalam proses pembelajaran, sehingga terjadi pergeseran pembelajaran dari perkuliahan formal menuju pembelajaran mandiri.

Inovasi dalam pembelajaran sering dihubungkan dengan pembaharuan yang berasal dari hasil pemikiran kreatif, temuan dan modifikasi yang memuat ide dan metode yang dipergunakan untuk mengatasi suatu permasalahan pembelajaran. Sedangkan model pembelajaran adalah suatu rencana atau pola yang dapat dipergunakan untuk membangun kurikulum, mendesain bahan instruksional dan sebagai pengarah terhadap kegiatan pembelajaran di dalam kelas atau di luar kelas. ${ }^{4}$ Model pembelajaran harus dapat berfungsi sebagai alat komunikasi dalam penyampaian materi kuliah. Agar inovasi model pembelajaran berhasil optimum sesuai dengan tujuan yang diinginkan maka beberapa hal perlu dipertimbangkan dalam inovasi seperti rasional teoritis, landasan pemikiran pembelajaran dan lingkungan belajar. Model pembelajaran dapat diakui apabila dapat dipergunakan secara luas dalam pembelajaran dan terbukti efektif dalam meningkatkan hasil belajar (prestasi belajar mahasiswa). Dengan demikian, model pembelajaran sebaiknya fleksibel dan bertanggungjawab terhadap hasil dan tujuan pembelajaran sehingga penyampaian materi menjadi terfokus. 


\section{INOVASI MODEL PEMBELAJARAN SAINS}

Inovasi model pembelajaran sains adalah suatu pendekatan pengajaran meliputi strategi, metode dan prinsip pengajaran yang dipergunakan dalam pembelajaran bidang sains. Model pembelajaran bidang sains memiliki kelebihan dalam tiga aspek, yaitu (1) pembelajaran pemecahan masalah, (2) pembelajaran berdasarkan pengalaman, dan (3) pembelajaran berbasis individu dan kerjasama. Pembelajaran pemecahan masalah dilakukan untuk menuntun mahasiswa melakukan penyelidikan melalui permasalahan bermakna yang diajukan oleh dosen dalam perkuliahan. Pembelajaran ini akan membawa mahasiswa pada situasi nyata sehingga dapat menuntun mahasiswa membangun pengetahuan dan keterampilan melalui pembelajaran mandiri. Pembelajaran berdasarkan pengalaman dilakukan untuk menjelaskan pengalaman belajar yang dimiliki dosen kepada mahasiswa. Pembelajaran ini dapat disampaikan melalui demonstrasi terhadap pengetahuan atau keterampilan yang dimiliki oleh dosen sehingga mahasiswa memperoleh pengetahuan dan ketrampilan standar dalam melakukan kegiatan akademik, misalnya dalam percobaan atau praktikum. Pembelajaran berbasis individu dan kerjasama dilakukan untuk membantu mahasiswa memahami konsep-konsep materi kuliah yang sulit, terutama bagi mahasiswa dengan tingkat kemampuan akademik berbeda. Model pembelajaran ini memberikan kesempatan kepada mahasiswa untuk menyelesaikan tugas yang diberikan oleh dosen secara mandiri maupun secara berkelompok dalam memecahkan permasalahan dalam kehidupan nyata melalui kegiatan kelas dan laboratorium. Model ini mampu membawa mahasiswa untuk dapat belajar aktif sehingga terjadi interaksi di antara mahasiswa. ${ }^{5}$

Inovasi model pembelajaran sains juga mengalami perkembangan sejalan dengan kemajuan dan perkembangan teknologi. Melalui inovasi maka model pembelajaran yang ada dikembangkan dan ditingkatkan untuk melahirkan model-model pembelajaran baru yang menarik. Dalam diskusi ini, beberapa inovasi model pembelajaran yang dipergunakan dalam pembelajaran sains akan dibahas, diantaranya adalah (a) Model pembelajaran menggunakan analogi, (b) Model pembelajaran menggunakan media, dan (c) Model pembelajaran berbasis teknologi informasi (web). Masing-masing model pembelajaran ini akan dijelaskan secara singkat berikut ini.

\section{Model Pembelajaran Menggunakan Analogi}

Model pembelajaran menggunakan analogi adalah pembelajaran yang menggunakan analogi dalam penjelasan fenomena ilmiah. Model 
pembelajaran menggunakan analogi sangat berperan dalam penjelasan ilmiah, pengamatan dan penemuan. Model pembelajaran ini dilakukan untuk menolong mahasiswa mengaplikasikan pengetahuan dan keadaan lingkungan nyata yang relevan pada saat mempelajari pengetahuan baru. Sebagai contoh, model pembelajaran dengan menggunakan analogi antara pergerakan planet dengan arah pergerakan jarum jam, pembelajaran menggunakan visualisasi analogi antara lemari buku dengan model atom Bohr, dan visualisasi analogi antara aliran air dengan aliran listrik, serta pembelajaran visualisasi analogi proses fotosinteis dengan dapur. ${ }^{6}$

Banyak pembelajaran sains yang kompleks dapat dijelaskan menggunakan analogi, terutama untuk menjelaskan konsep-konsep ilmiah di dalam buku ajar. Akan tetapi, model pembelajaran menggunakan analogi sangat sulit dilakukan oleh dosen yang kurang berpengalaman. Kehatihatian dan pertimbangan yang cukup matang harus dilakukan dalam menggunakan analogi di dalam pembelajaran karena analogi yang kurang memadai akan membingungkan mahasiswa. Agar pembelajaran dapat efektif menggunakan analogi maka dosen dalam mendesain model pembelajaran analogi harus melakukan langkah-langkah sebagai berikut: (1) memperkenalkan konsep target sehingga topik yang akan dianalogikan jelas, (2) menunjukkan analogi yang sesuai dan mudah dipahami dengan menggunakan bahan, materi atau lingkungan nyata, (3) mengidentifikasi bagian yang relevan dari suatu target dengan analogi yang dipersiapkan, (4) menentukan kesesuaian antara konsep target dengan analogi yang ditunjukkan, (5) menyatakan bagian-bagian yang beranalogi, dan (6) membuat kesimpulan.

\section{Model Pembelajaran Menggunakan Media}

Media pembelajaran dapat dipergunakan untuk membangun pemahaman dan penguasaan objek pembelajaran. Beberapa media pembelajaran yang sering dipergunakan dalam pembelajaran diantaranya media cetak, elektronik, model dan peta. ${ }^{7}$ Media cetak banyak dipergunakan untuk pembelajaran dalam menjelaskan materi kuliah yang kompleks sebagai pendukung buku ajar. Pembelajaran dengan menggunakan media cetak akan lebih efektif jika bahan ajar sudah dipersiapkan dengan baik yang dapat memberikan kemudahan dalam menjelaskan konsep yang diinginkan kepada mahasiswa.

Media elektronik seperti video banyak dipergunakan di dalam pembelajaran sains. Penggunaan video sangat baik dipergunakan untuk membantu pembelajaran, terutama untuk memberikan penekanan pada materi kuliah yang sangat penting untuk diketahui oleh mahasiswa. Harus 
disadari bahwa video bukan diperuntukkan untuk menggantungkan pengajaran pada materi yang diperlihatkan pada video, sehingga pengaturan penggunaan waktu dalam menggunakan video sangat perlu, misalnya maksimum 20 menit. Inovasi model pembelajaran dengan menggunakan video dalam percobaan yang menuntut keterampilan seperti pada kegiatan praktikum sangat efektif bila dilakukan dengan penuh persiapan. Sebelum praktikum dimulai, video dipergunakan untuk membantu mahasiswa memberikan arahan terhadap apa yang harus mereka amati selama percobaan. Selanjutnya, video diputar kembali pada akhir praktikum untuk mengklarifikasi hal-hal penting yang harus diketahui oleh mahasiswa dari percobaan yang sudah dilakukan.

Media lain yang dipergunakan dalam pembelajaran sains adalah peta konsep. Penggunaan media peta konsep di dalam pembelajaran sudah dilakukan sejak tahun 1977, yaitu dalam pengajaran Biologi, dan sejak itu media peta konsep berkembang dan telah dipergunakan dalam pembelajaran sains. ${ }^{8}$ Media peta konsep bertujuan untuk membangun pengetahuan siswa dalam belajar secara sistematis, yaitu sebagai teknik untuk meningkatkan pengetahuan siswa dalam penguasaan konsep belajar dan pemecahan masalah. ${ }^{9}$ Peta konsep merupakan media pembelajaran yang dapat menunjukkan konsep ilmu yang sistematis, yaitu dimulai dari inti permasalahan sampai pada bagian pendukung yang mempunyai hubungan satu dengan lainnya, sehingga dapat membentuk pengetahuan dan mempermudah pemahaman suatu topik pelajaran. Langkah yang dilakukan dalam inovasi model pembelajaran dengan media peta konsep adalah memikirkan apa yang menjadi 'pusat' topik yang akan diajarkan, yaitu sesuatu yang dianggap sebagai konsep 'inti' dimana konsep-konsep pendukung lain dapat diorganisasikan terhadap konsep inti, kemudian menuliskan kata, peristilahan dan rumus yang memiliki arti, yaitu yang mempunyai hubungan dengan konsep inti, dan pada akhirnya membentuk satu peta hubungan integral dan saling terkait antara konsep atas-bawah-samping.

\section{Model Pembelajaran Berbasis Teknologi Informasi}

Adaptasi teknologi baru terhadap kebutuhan pembelajaran bidang sains menjadi salah satu sasaran inovasi model pembelajaran. Kemajuan dalam teknologi komunikasi dan informasi telah memudahkan manusia untuk dapat saling berhubungan dengan cepat, mudah dan terjangkau serta potensil untuk inovasi model pembelajaran. Perkembangan teknologi informasi sangat berpengaruh terhadap inovasi model pembelajaran. Penemuan berbagai jenis teknologi yang dapat digunakan menjadi fasilitas pembelajaran seperti komputer, CD-ROM dan LAN telah mendorong 
pemanfaatnya dalam inovasi model pembelajaran. Pendekatan penggunaan teknologi baru yang dipadukan dengan teori paedagogik telah melahirkan pembelajaran e-learning. ${ }^{10}$ E-learning telah memberikan pengaruh sangat besar dalam inovasi model pembelajaran. E-Learning identik dengan penggunaan teknologi internet untuk menyampaikan materi kuliah. Sensitivitas pembelajaran sains terhadap perubahan dan kemajuan yang sangat cepat mengharuskannya untuk menggunakan teknologi informasi dalam komunikasi dan pembelajaran. Inovasi model pembelajaran berbasis teknologi informasi diawali dari penggunaan komputer dalam pembelajaran secara offline dan kemudian berkembang dengan penggunaan web dalam pembelajaran secara online.

\section{Pembelajaran Menggunakan Komputer}

Penggunaan komputer dalam pembelajaran sains sangat menguntungkan karena dapat memberikan kesempatan luas kepada mahasiswa dan dosen untuk mengembangkan kemampuannya dalam investigasi dan analisis, sekaligus dapat membentuk pengetahuan dan pemahaman yang baru dalam melihat suatu permasalahan, serta mendapatkan cara pemecahan masalah melalui pembelajaran. Pembelajaran menggunakan komputer sangat baik digunakan dalam pengumpulan, visualisasi dan analisis data sederhana dan kompleks. Dengan menggunakan komputer maka pengumpulan data dapat dilakukan sebanyak mungkin, visualisasi data dapat dilakukan bervariasi, dan pengolahan data dapat dilakukan sangat cepat setelah mendapatkan data pengamatan dari percobaan laboratorium. Banyak studi telah dilakukan yang menjelaskan pentingnya penggunaan komputer dalam pembelajaran sains. ${ }^{11}$ Saat ini penggunaan komputer sebagai alat belajar sangat menguntungkan karena telah tersedia berbagai jenis software dan hardware yang memudahkan untuk mengintegrasikan komputer dengan peralatan elektronik lain seperti video, camera dan instrumen laboratorium. Penggunaan komputer dalam pembelajaran akan dapat meningkatkan efisiensi dan efektivitas pembelajaran, akan tetapi membutuhkan inovator yang terampil dan berpengalaman.

Pertimbangan utama yang dibutuhkan dalam penggunaaan komputer dalam pembelajaran adalah ketersediaan dan kemauan dosen (inovator) untuk menggunakannya dalam inovasi model pembelajaran. Misalnya, seorang dosen telah melakukan inovasi pembelajaran untuk materi kuliah tertentu menggunakan PC di rumahnya, tetapi komputer yang tersedia di kampus tidak mampu mengoperasikan pembelajaran tersebut karena keterbatasan dalam software maupun hardware sehingga akan menghambat pengembangan inovasi itu sendiri. Ketidaksiapan mahasiswa dan dosen dalam mengaplikasikan model pembelajaran yang disebabkan oleh keter- 
batasan pengetahuan dalam pengoperasian komputer dalam pembelajaran juga dapat menjadi kendala dalam inovasi model pembelajaran.

\section{Pembelajaran Menggunakan Web}

Penggunaan komputer sebagai alat bantu komunikasi dan pembelajaran telah dilakukan di perguruan tinggi dan menganggapnya sebagai satu kewajiban dan kebutuhan.12 Perkembangan penggunaan komputer dalam pembelajaran telah mendorong pengaturan peralatan komputer sebagai alat bantu belajar yang disebut dengan computer managed learning (CML). CML didesain untuk membantu mahasiswa dalam jumlah besar dapat belajar secara mandiri dari sumber belajar yang sudah disediakan dalam komputer, LAN dan world wide web (www). Model pembelajaran menggunakan CML menguntungkan karena kepada mahasiswa diberikan kebebasan untuk mendapatkan berbagai jenis sumber belajar yang tersedia sesuai dengan kebutuhan dan kemampuannya. Pembelajaran CML menyediakan berbagai jenis metodologi yang disesuaikan dengan materi kuliah yang akan diberikan kepada mahasiswa, sehingga mahasiswa dapat memilih cara termudah dan yang sesuai dengan kemampuannya. CML melalui web sangat efisien untuk penyampaian materi kuliah dan memberikan kesempatan kepada mahasiswa belajar dari mana saja dan kapan saja tanpa dibatasi tempat dan waktu belajar. ${ }^{13}$

Pada saat ini inovasi model pembelajaran dengan menggunakan komputer berkembang sangat pesat terutama setelah tersedianya komputer "superhighway" dan "internet". Melalui internet maka kendala keterjangkauan terhadap informasi antar perguruan tinggi dan sumber belajar dapat diatasi. Internet bukan hanya sebagai sarana informasi dan komunikasi, tetapi merupakan sumber belajar yang sangat penting karena materi pembelajaran saat ini sudah banyak yang tersedia di dunia maya (web). Sumber belajar melalu internet ini sangat dibutuhkan oleh dosen di dalam meningkatkan kualitas pengajarannya. Prinsip utama model pembelajaran berbasis web adalah memberikan tanggung jawab besar terhadap mahasiswa. Pembelajaran berbasis web memberikan kebebasan kepada mahasiswa dalam pengelolaan waktu belajar sehingga mahasiswa dapat mengoptimalkan pembelajarannya dengan cara menggunakan sumber belajar dalam waktu tidak terbatas. Penggunaan internet dalam pembelajaran sangat menguntungkan bagi mahasiswa dan dosen karena dapat mengakses informasi ilmiah secara lengkap dan jelas.

Inovasi pembelajaran berbasis web dalam pembelajaran sains banyak yang sudah berhasil seperti dijelaskan oleh Cann dan Dickneider. ${ }^{14}$ Biasanya bahan ajar yang disediakan dalam pengajaran berbasis web terdiri atas 
modul yang dilengkapi dengan instruksi penggunaannya. Materi kuliah dapat juga disertai dengan presentasi Power Point yang dapat diakses oleh mahasiswa secara online. Pembelajaran berbasis web harus dilengkapi dengan berbagai jenis software yang dapat diakses dan didownload oleh mahasiswa sehingga materi kuliah dan bahan yang diperlukan oleh mahasiswa dapat diakses sendiri oleh mahasiswa tanpa harus dituntun oleh dosen. Tersedianya fasilitas yang lengkap di dalam web akan memberi peluang bagi mahasiswa untuk mempelajari semua materi yang disediakan secara optimum. Model pembelajaran web ini juga menyediakan fasilitas "pertolongan" (help) bagi mahasiswa yang mengalami kesulitan dalam mengerti materi pembelajaran.

Model pembelajaran berbasis web juga harus menyediakan bahan evaluasi berupa bank soal dalam berbagai variasi, sederhana dan mudah untuk dikerjakan dan hasil penilaian cepat diperoleh. Pada umumnya evaluasi didesain dalam bentuk pilihan berganda, benar-salah, dan jawaban singkat dengan jumlah kata terbatas. Untuk membantu mahasiswa mengetahui apakah jawabannya benar atau salah maka hasil penilaian harus dapat diperoleh secara online. Fasilitas remedial juga harus tersedia untuk menolong mahasiswa dalam meningkatkan pengetahuannya dan memperoleh jalan keluar apabila jawabanya tidak benar. Pembelajaran menggunakan internet memang sulit untuk diikuti di beberapa perguruan tinggi di Indonesia karena cepatnya perubahan yang terjadi dalam bidang penelitian dan pengembangan sering tidak diikuti oleh penyediaan dana dan fasilitas pendukung.

\section{KOMPONEN YANG PERLU DALAM INOVASI MODEL PEMBELAJARAN}

Beberapa komponen yang perlu dibenahi agar inovasi model pembelajaran dapat efektif untuk meningkatkan prestasi belajar mahasiswa adalah dosen profesional, mahasiswa, sarana dan prasarana pembelajaran, proses pembelajaran, kurikulum, monitoring dan evaluasi. Masing-masing komponen ini akan dijelaskan secara singkat sebagai berikut.

\section{Dosen Profesional}

Dosen yang profesional sangat menentukan dalam inovasi model pembelajaran karena berhubungan dengan peningkatan kualitas pembelajaran. Profesionalisme dosen meliputi penguasaan ilmu pengetahuan atau kemampuan manajemen beserta strategi penerapannya. Dosen profesional dituntut untuk mempunyai komitmen kepada mahasiswa dalam pembelajaran, menguasai materi kuliah yang diajarkan serta mengetahui cara pembelajarannya, bertanggung jawab memantau hasil belajar maha- 
siswa melalui berbagai jenis evaluasi, mampu berpikir sistematis tentang apa yang dilakukannya dan belajar dari pengalamannya. Dosen profesional akan selalu berusaha untuk melakukan inovasi model pembelajaran untuk memudahkan penyampaian materi kuliah kepada mahasiswa.

Dalam proses pembelajaran, hasil belajar mahasiswa sangat dipengaruhi oleh faktor berikut: (1) Gaya pribadi dosen dan bentuk pengajaran yang digunakan, termasuk diantaranya adalah nada suara, perhatian dan penekanan; (2) Materi pelajaran yang disajikan, dan (3) Keterampilan atau teknik penyampaian materi kuliah yang digunakan. Faktor (1) dan (2) mungkin sulit untuk diubah, akan tetapi faktor (3) dapat dengan mudah diperbaiki melalui pembelajaran dan pengalaman. Agar pengajaran berhasil dengan baik maka beberapa hal yang perlu diperhatikan, yaitu persiapan, pelaksanaan dan umpan balik. Persiapan pengajaran yang baik akan dapat digunakan sebagai jaminan hasil dalam pelaksanaan pembelajaran. Persiapan bukan hanya mempelajari apa yang akan diajarkan. Yang utama dalam persiapan pengajaran adalah strategi penyusunan materi kuliah dan pengaturan penyampaian materi agar lebih sistematis dan mudah dimengerti. Dalam hal ini perlu inovasi model pembelajaran yang sesuai untuk penyampaian materi kuliah. Keterbatasan pengetahuan inovator akan menjadi penghalang dalam inovasi model pembelajaran.

\section{Mahasiswa}

Agar mutu pembelajaran dapat ditingkatkan, maka tidak terlepas dari mahasiswa yang ikut serta dalam proses pembelajaran. Mahasiswa harus ditempatkan sebagai pusat kegiatan pembelajaran sehingga inovasi model pembelajaran harus selalu mempertimbangkan kebutuhan mahasiswa. Hal yang harus selalu dipikirkan bahwa kelompok mahasiswa yang berbeda mempunyai kemampuan berbeda, sehingga memotivasi mahasiswa dalam kegiatan pembelajaran sangat diperlukan karena rendahnya daya juang mahasiswa seperti sekarang ini akan mengakibatkan keengganan belajar, yang pada akhirnya akan mempengaruhi terhadap kualitas lulusan. Untuk memotivasi mahasiswa dalam belajar diperlukan inovasi model pembelajaran agar proses pembelajaran dapat memberikan suasana kondusif terhadap mahasiswa dan dapat menuntun mereka belajar aktif, bebas menggali dan membentuk kompetensi ilmu, keterampilan, sikap perilaku dan kepribadian profesi.

\section{Sarana dan Prasarana Pembelajaran}

Sarana dan prasarana pembelajaran sangat menentukan dalam penerapan inovasi model pembelajaran. Inovasi model pembelajaran akan 
sulit berkembang bila tidak didukung oleh sarana dan prasarana pembelajaran. Penyediaan dan penggunaan sarana dan prasarana pembelajaran secara optimum akan dapat meningkatkan kualitas pembelajaran. Gedung dan ruang kuliah serta perlengkapannya perlu mendapat perhatian dari segi kelayakannya untuk mendukung penerapan model pembelajaran yang dipersiapkan. Laboratorium sebagai ajang latihan dan praktek mahasiswa perlu dilengkapi dengan fasilitas yang sesuai untuk inovasi pembelajaran. Lemahnya faktor penunjang sarana dan prasarana akan menjadi kendala dalam inovasi model pembelajaran. Keterbatasan keuangan yang tidak terpenuhi dalam mendukung pelaksanaan inovasi model pembelajaran juga harus disiasati dalam mensukseskan inovasi model pembelajaran.

\section{Proses Pembelajaran}

Proses pembelajaran sangat berpengaruh terhadap keberhasilan inovasi model pembelajaran dan juga inovasi model pembelajaran dapat meningkatkan proses pembelajaran. Tujuan pembelajaran bukanlah hanya semata-mata transfer pengetahuan dan keterampilan, yaitu menjadikan mahasiswa dari tidak tahu manjadi tahu, akan tetapi harus mampu membina mahasiswa manjadi kreatif, mahir dan terampil. Proses pembelajaran hendaknya mampu menumbuhkan, menyempurnakan dan meningkatkan pola laku tertentu dalam diri mahasiswa, yaitu kerangka dasar dari kegiatan yang dilakukan oleh manusia dalam usaha mempertahankan hidup di masyarakat agar mahasiswa dapat bertindak secara rasional dan mampu menimbulkan kebiasaan baik bagi diri sendiri.

Dosen harus menyadari pesatnya perkembangan teknologi dan informasi saat ini yang mengarah pada terjadinya peradaban manusia menjadi global. Informasi terkini secara bebas telah dapat diakses oleh mahasiswa. Informasi tersebut mungkin masih tabu bagi sebagian orang, atau mungkin bagi orang lain sulit untuk dijelaskan, sehingga banyak perubahan-perubahan yang telah terjadi menjadi membingungkan. Oleh sebab itu, agar komunikasi antara dosen dan mahasiswa berjalan dengan baik maka inovasi model pembelajaran juga harus disesuaikan dengan perubahan yang terjadi. Dosen harus memberikan kesempatan dan ruang gerak kepada mahasiswa untuk menjelaskan apa yang sudah mereka ketahui dan menanyakan apa yang mereka inginkan. Dengan demikian, inovasi model pembelajaran harus dapat menggairahkan proses pembelajaran agar mahasiswa dibina dan diarahkan untuk memiliki pola pikir, keterampilan dan kebiasaan terbuka, tanggap dan mampu menyesuaikan diri dengan lingkungannya. 


\section{Kurikulum}

Inovasi model pembelajaran tidak dapat dipisahkan dari kurikulum pembelajaran. Untuk menghasilkan model pembelajaran yang berkualitas maka kurikulum yang digunakan juga harus mengikuti program-program yang ada di dalamnya. Dalam penerapan model pembelajaran hendaknya disesuaikan dengan perubahan kurikulum atau perubahan kurikulum diikuti dengan pembaharuan model pembelajaran atau perubahan secara bersama-sama. Menyelaraskan model pembelajaran dengan kurikulum dapat dilakukan dengan melibatkan mahasiswa dan dosen untuk memberikan masukan yang berguna kepada inovator dalam melakukan inovasi model pembelajaran yang lebih baik.

\section{Evaluasi dan Monitoring}

Agar model pembelajaran dapat berjalan dengan baik maka semua pihak harus dilibatkan dalam inovasi sebelum penerapannya di lapangan. Evaluasi dan monitoring harus dilakukan untuk mengetahui tingkat penolakan dari sekelompok tertentu atas hasil inovasi. Evaluasi sangat penting untuk mengetahui tingkat keberhasilan model pembelajaran, yaitu melihat pengaruh model pembelajaran dalam meningkatkan prestrasi belajar mahasiswa. Melalui hasil evaluasi akan diketahui kekuatan dan kelemahan model pembelajaran terutama bila memerlukan penyempurnaan pada penggunaan berikutnya.

\section{KESIMPULAN}

Inovasi model pembelajaran sangat diperlukan dalam peningkatan penguasaan mahasiswa terhadap materi perkuliahan. Keberhasilan inovasi model pembelajaran dalam meningkatkan prestasi mahasiswa sangat ditentukan oleh kesesuaian model pengajaran dengan materi kuliah dan tujuan pembelajaran. Beberapa komponen yang perlu dipertimbangkan dalam inovasi model pembelajaran adalah dosen, mahasiswa, sarana dan prasarana pembelajaran, proses pembelajaran, kurikulum, monitoring dan evaluasi. Hasil penelitian menunjukkan bahwa model pembelajaran menggunakan media peta konsep, model pembelajaran menggunakan komputer, dan model pembelajaran berbasis web yang dimodifikasi sangat efektif dalam meningkatkan prestasi belajar mahasiswa.

\section{CATATAN AKHIR:}

1. Shakkashiri, B.Z., Chemical Demonstration. A hand book for teacher of chemistry, The University of Winconsin Press, 1991, h. 215. 
2. Lynch, P.P., dan Waters, M., Expectation of New Chemistry Students Concerning Chemistry Courses, Chemistry in Australia, 47: 238-242, 1980, h. 240.

3. Boyce, L.N., VanTasselBaska, J., Burruss, J.D., Sher, B.T., dan Johnson, D.T., A Problem-Based Curriculum: Parallel Learning Opportunities for Students and Teachers, Journal of the Education of the Gifted, 20: 363-379, 1997, h. 364.

4. Joice, B. dan Weil, M., Models of Teaching, 2nd ed., Prentice-Hall International Inc. Englewood Cliffs, New Jersey, 1980, h. 45.

5. Giancarlo, L.C., dan Slunt, K.M., Thedog ate my homework: A Cooperative Learning Project For Instrumental Analysis, Journal of Chemical Education 81: 868-869, 2004, h. 868.

6. Glynn, S.M., Law, M., Gibson, N.M., dan Hawkins, C.H., Teaching Science With Analogies, A Resource For Teachers And Text Book Authors, University of Georgia, 2001. Lihat juga Khalifah, M., Pengaruh Model Pembelajaran Synectics yang Dipadu Mind Maps dan Strategi Kooperatif terhadap Berpikir Kreatif, Sikap Kreatif, dan Penguasaan Materi Biologi Siswa SMP Kota Makassar yang Berkemampuan Tinggi dan Rendah, Disertasi, UM, Malang, 2007, h. 215.

7. Kreyenbuhl, J.A. dan Atwood, C.H., Are We Teaching the Right Things in General Chemistry?, Journal of Chemical Education 68: 914-918, 1991, h. 916.

8. Novak, J.D., New trends in Biology teaching, Science Education 61: 453-477, 1977, h. 916, h. 455.

9. Pandley, B.D., Bretz, R.L., dan Novak, J.D., Concept maps as a tools to assess learning in chemistry, Journal of Chemical Education 71: 9-15, 1994, h. 12.

10. Rosenberg, M.J., E-Learing Strategies for Delivering Knowledge in the Digitalage, McGraw-Hill, New York, 2001, h. 97.

11. Lazarowictz, R., dan Tamir, P., Research on using laboratory instruction in science: in D. Gabel (Ed), Hand Book Of Research On Science Teaching And Learning, Macmillan, New York, 1994, h. 124.

12. Slocum, L.E., Towns, M.H., dan Zielinski, T.J., Online chemistry Module: Interaction and effective faculty facilitation, Journal of Chemical Education, 81: 1058-1065, 2004, h. 1059.

13. Forsyth, I., Jolliffe, A., dan Stevens, D., Practical Strategies For Teachers, Lecturers and Trainers, Delivering, Vol 3, Crest Publishing House, New Delhi, 2004, h. 83.

14. Cann, M.C., dan Dickneider, T.A., Infusing The Chemistry Curriculum With Green Chemistry Using Real-World Examples, Web Modules, And Atom Economy In Organic Chemistry Course, Journal of Chemical Education, 81: 977980, 2004, h. 978.

\section{DAFTAR PUSTAKA:}

Boyce, L.N., VanTasselBaska, J., Burruss, J.D., Sher, B.T., dan Johnson, D.T., A Problem-Based Curriculum: Parallel Learning Opportunities for Students and Teachers, Journal of the Education of the Gifted, 20:363-379, 1997.

Cann, M.C., dan Dickneider, T.A., Infusing The Chemistry Curriculum With Green Chemistry Using Real-World Examples, Web Modules, And Atom Economy In Organic Chemistry Course, Journal of Chemical Education, 81: 977-980, 2004.

Forsyth, I., Jolliffe, A., dan Stevens, D., Practical Strategies For Teachers, Lecturers and Trainers, Delivering, Vol 3, Crest Publishing House, New Delhi, 2004. 
Giancarlo, L.C., dan Slunt, K.M., Thedog ate my homework: A Cooperative Learning Project For Instrumental Analysis, Journal of Chemical Education, 81: 868-869, 2004.

Glynn, S.M., Law, M., Gibson, N.M., dan Hawkins, C.H., Teaching Science With Analogies, A Resource For Teachers And Text Book Authors, University of Georgia, 2001.

Joice, B. dan Weil, M., Models of Teaching, 2nd ed., Prentice-Hall International Inc. Englewood Cliffs, New Jersey, 1980.

Khalifah, M, Pengaruh Model Pembelajaran Synectics yang Dipadu Mind Maps dan Strategi Kooperatif terhadap Berpikir Kreatif, Sikap Kreatif, dan Penguasaan Materi Biologi Siswa SMP Kota Makassar yang Berkemampuan Tinggi dan Rendah. Disertasi, UM, Malang, 2007.

Kreyenbuhl, J.A. dan Atwood, C.H., Are We Teaching the Right Things in General Chemistry?, Journal of Chemical Education, 68: 914-918, 1991.

Lazarowictz, R., dan Tamir, P., Research on using laboratory instruction in science: in D. Gabel (Ed), Hand Book Of Research On Science Teaching And Learning, Macmillan, New York, 1994.

Lynch, P.P., dan Waters, M., Expectation of New Chemistry Students Concerning Chemistry Courses, Chemistry in Australia, 47: 238-242, 1980.

Novak, J.D., New trends in Biology teaching, Science Education, 61: 453-477, 1977.

Pandley, B.D., Bretz, R.L., dan Novak, J.D., Concept maps as a tools to assess learning in chemistry, Journal of Chemical Education, 71: 9-15, 1994.

Rosenberg, M.J., E-Learing Strategies for Delivering Knowledge in the Digitalage, McGraw-Hill, New York, 2001.

Shakkashiri, B.Z., Chemical Demonstration, A hand book for teacher of chemistry, The University of Winconsin Press, 1991.

Slocum, L.E., Towns, M.H., dan Zielinski, T.J., Online chemistry Module: Interaction and effective faculty facilitation, Journal of Chemical Education, 81: 1058-1065, 2004.

UNSW (2003), http://www.chem.unsw.edu.au/undergrad/unotes.htm (accessed Agustus-Oktober 2003). 